\title{
Preparação e Caracterização de Nanofibras de Celulose a partir de Bagaço de Mandioca
}

\author{
Isabella S. Silvestre \& Rita de Cássia Bergamasco
}

O presente trabalho teve como objetivo o isolamento de nanofibras de celulose presentes no bagaço de mandioca resultante do processamento do polvilho. $\mathrm{O}$ bagaço foi tratado com $\mathrm{NaOH}$, branqueado com $\mathrm{NaClO} 2$ em solução tampão acetato e, por fim, passou por hidrólise ácida com $\mathrm{HCl}$ em concentrações de 0,1 e 0,3 M. O material foi analisado a cada etapa, passando pelas técnicas de análise termogravimétrica (TGA), espectroscopia de absorção na região do infravermelho (FTIR) e microscopia eletrônica de varredura (MEV). Foi constatado que o tratamento alcalino retirou amido e compostos de baixa estabilidade térmica, o branqueamento retirou parte da lignina e o tratamento ácido retirou parte da lignina e hemicelulose, tornando possível a obtenção de nanofibras de celulose do bagaço de mandioca através de tais tratamentos químicos.

Palavras Chave: nanofibras; celulose; hidrólise àcida.

This study had as objective the isolation of cellulose nanofibers present in cassava bagasse resulting of tapioca flour processing. The pulp was treated with $\mathrm{NaOH}$, bleached with $\mathrm{NaClO} 2$ in buffered solution and lastly, underwent acid hydrolysis with $\mathrm{HCl}$ in concentrations of 0,1 and $0,3 \mathrm{M}$. The material was analyzed at each stage, undergoing analysis techniques such as termogravimetric analysis (TGA), Fourier transform infrared spectroscopy (FTIR) and scanning electron microscopy (SEM). It was verified that the alkaline treatment removed starch and low termical stability compounds, the bleaching removed part of lignin and the acid treatment removed lignin and hemicellulose, making possible the obtainment of cellulose nanofibers from cassava bagasse through these chemical treatments.

Keywords: nanofibres; cellulose; acid hydrolysis. 


\section{Introdução}

Com o crescente interesse pela busca de materiais biodegradáveis, estão sendo realizados diversos estudos envolvendo nanofibras de celulose. Estas podem ser aplicadas em indústrias de papel, construção civil, materiais plásticos, cosméticos, entre outras, conferindo aos produtos melhorias na qualidade e nas propriedades (NUNES, 2014). Atualmente, muitos estudos envolvendo nanofibras são direcionados para sua aplicação em filmes biodegradáveis, reforçando sua estrutura. Tais fibras podem ser obtidas a partir de inúmeras fontes, mas é importante considerar a disponibilidade destas no mercado.

A mandioca é um produto de grande importância nacional. Segundo a CONAB (2017), o Brasil é o quarto maior produtor do mundo, sendo responsável em 2014 por aproximadamente 8,6\% da produção global, com 23,24 milhões de toneladas. Grande parte dessa produção é utilizada na fabricação de polvilho, a qual gera como subproduto o bagaço de mandioca. Este é composto, principalmente, por fibras celulósicas e amido residual, e sua alta umidade (superior a $80 \%$ ) desestimula seu reaproveitamento industrial, que estaria relacionado a altos custos de secagem ou transporte e alta perecibilidade. Geralmente esse produto é descartado, muitas vezes de forma inapropriada, ou destinado à alimentação animal, no entanto a produção de nanofibras de celulose pode ser uma maneira de agregar valor a este, como também resolver o problema do descarte (JASKO et al., 2011).

Desta forma, pode-se perceber que há grande disponibilidade de bagaço de mandioca no Brasil, o qual pode ser uma potencial fonte de nanofibras de celulose. No entanto, a estrutura do bagaço de mandioca não é homogênea: além da celulose, estão presentes no material outros polissacarídeos, como a lignina e a hemicelulose que ficam entrelaçadas na matriz celulósica, além do amido. Deve-se, portanto, quebrar essa estrutura para isolar a celulose.

Outros trabalhos já desenvolvidos na área, como o de
Ruangudomsakul et al (2015), mostram que é possível isolar as fibras celulósicas através de tratamentos químicos, sendo feito primeiramente um prétratamento que consiste na hidrólise alcalina, seguido do branqueamento e por fim o tratamento principal, que pode ser feito por hidrólise ácida, enzimática ou por oxidação. Grande parte destes trabalhos usa o $\mathrm{H}_{2} \mathrm{SO}_{4}$ para a hidrólise ácida. Já este trabalho visa a utilização do $\mathrm{HCl}$, uma vez que é menos agressivo e mais seguro para o trabalho em laboratório. A caracterização do material é feita através da espectroscopia de absorção na região do infravermelho (FTIR), análise termogravimétrica (TGA) e microscopia eletrônica de varredura (MEV).

Assim, este trabalho tem como objetivo a obtenção de nanofibras de celulose a partir de tratamentos químicos alcalino, de branqueamento e ácido com $\mathrm{HCl}$ sobre o bagaço de mandioca e a caracterização de sua estrutura, estabilidade térmica e comportamento químico a cada etapa de tratamento, para posterior aplicação em filmes biodegradáveis.

\section{Metodologia}

$O$ bagaço de mandioca foi cedido pela empresa CAPROMAL - Cacique Produtos de Mandioca LTDA. Os reagentes utilizados foram o hidróxido de sódio $(\mathrm{NaOH})$ em pérolas, clorito de sódio ( $\mathrm{NaClO} 2) 80 \%$, ácido acético glacial $(\mathrm{CH} 3 \mathrm{COOH}) \quad 99,5 \%$ e ácido clorídrico $(\mathrm{HCl}) 37 \%$. Foi utilizada a metodologia de Ruangudomsakul et al (2015) e foram obtidas cinco amostras no total.

O bagaço úmido foi desidratado em estufa a $40^{\circ} \mathrm{C}$ por 24 horas. O material foi moído em liquidificador de potência $600 \mathrm{~W}$ e em seguida peneirado em peneira 100 mesh $(0,149 \mathrm{~mm})$. Disto, obteve-se a amostra 1. Então, o bagaço em pó passou pelo tratamento alcalino, no qual foi misturado com uma solução de $\mathrm{NaOH} 4 \%(\mathrm{~m} / \mathrm{m})$ e agitado constantemente por 2 horas, sob a temperatura de $80^{\circ} \mathrm{C}$ em banho termostático, na razão de $20 \mathrm{~mL}$ de solução por grama de bagaço em pó. Ao fim, este foi lavado e filtrado à vácuo com água destilada até atingir 
$\mathrm{pH}$ neutro. Uma parte do bagaço foi seca em estufa a $40^{\circ} \mathrm{C}$ por $24 \mathrm{~h}$ e representa a amostra ${ }^{2}$.

Preparou-se uma solução contendo tampão acetato (27g de $\mathrm{NaOH}$ em $75 \mathrm{~mL}$ de ácido acético glacial, diluído em $1 \mathrm{~L}$ de água destilada) e clorito aquoso (NaClO2) $1,7 \%$ na proporção 1:1. Em seguida, realizouse o branqueamento: o material resultante do tratamento alcalino foi misturado a essa solução previamente preparada na proporção de $1 \mathrm{~g}$ para $50 \mathrm{~mL}$ e mantido sob agitação a $80^{\circ} \mathrm{C}$, por 6 horas. Posteriormente, foi feita a filtragem e lavagem com água destilada em filtro à vácuo até pH neutro. Uma parte foi retirada e secada em estufa para análises, sendo a amostra ${ }^{3}$.

Por fim, realizou-se a hidrólise ácida a $40^{\circ} \mathrm{C}$ por 1 hora, sob agitação, na qual o material vindo do branqueamento foi misturado à solução de $\mathrm{HCl}$ na proporção de $1 \mathrm{~g}$ para $10 \mathrm{~mL}$ de ácido. O procedimento foi efetuado em duas concentrações molares diferentes: $0,1 \mathrm{M}$ e $0,3 \mathrm{M}$. Após isto, as soluções foram filtradas e lavadas com água no filtro à vácuo até $\mathrm{pH}$ neutro, e então submetidas a ultrassom durante 5 minutos. Feito isto, foram secas em estufa a $40^{\circ} \mathrm{C}$ durante $24 \mathrm{~h}$. O material resultante da hidrólise ácida a $0,1 \mathrm{M}$ corresponde à amostra 4 e o material da hidrólise a $0,3 \mathrm{M}$ corresponde à amostra $^{5}$.

As amostras foram submetidas às seguintes análises: TGA, FTIR e MEV.

\section{TGA}

A estabilidade térmica das amostras $1,2,3,4$ e 5 foi determinada em forno HT no Complexo de Centrais de Apoio à Pesquisa (COMCAP) da Universidade Estadual de Maringá, em porta amostra de platina, sob atmosfera de nitrogênio com fluxo de $10 \mathrm{~mL} / \mathrm{min}$, aquecendo a partir da temperatura ambiente até $800^{\circ} \mathrm{C}$.

\section{FTIR}

A espectroscopia vibracional foi realizada para as amostras 1, 2, 4 e 5 no intervalo espectral de 4000 a $400 \mathrm{~cm}-1$. Esta técnica foi realizada no Departamento de Física da Universidade Estadual de Maringá.

\section{MEV}

A estrutura do material das amostras 1, 2, 3, 4 e 5 foi analisada com a técnica de microscopia eletrônica de varredura no equipamento Quanta 250 localizado no Complexo de Centrais de Apoio à Pesquisa (COMCAP) da Universidade Estadual de Maringá. As amostras foram preparadas em fita de carbono e metalizadas com ouro. O equipamento foi operado a $15,00 \mathrm{kV}$.

\section{Resultados e Discussão}

\section{FTIR}

A Figura 1 mostra o espectro para as amostras 1, 2, 4 e 5. Em $800 \mathrm{~cm}-1$ encontra-se um pico típico da estrutura celulósica. O pico em $1043 \mathrm{~cm}-1$ indica vibração do estiramento do éter $\mathrm{C}-\mathrm{O}$ e as ligações $\beta-\mathrm{O}-4$ e metoxil. A intensidade relativa destes diminuiu após a hidrólise. Na região de 1200 a $1300 \mathrm{~cm}-1$ encontra-se picos associados ao estiramento $\mathrm{C}-\mathrm{O}$ da hemicelulose e lignina. A intensidade destes picos diminuiu no material tratado com $\mathrm{HCl}$, sendo atribuída à remoção parcial da lignina e hemicelulose. O pico de $1640 \mathrm{~cm}-1$ é atribuído à vibração do estiramento $-\mathrm{C}=\mathrm{O}$ cetona aril p-substituído. Sua intensidade relativa reduziu devido à degradação da lignina. $\mathrm{O}$ pico em $1730 \mathrm{~cm}-1$ indica grupos éster e acetil na hemicelulose ou grupos ácido carboxílico na lignina. Este pico desapareceu após o tratamento químico, indicando a remoção dos materiais não celulósicos. O pico localizado em $2900 \mathrm{~cm}-1$ mostra vibração do estiramento $\mathrm{C}-\mathrm{H}$. A intensidade de sua absorbância reduziu com o tratamento ácido, devido a presença da porção $-\mathrm{CH}_{2}$ na amostra. $\mathrm{O}$ pico em $3400 \mathrm{~cm}-1$ é atribuído à vibração do estiramento $\mathrm{O}-\mathrm{H}$ das pontes de hidrogênio. Esta intensidade relativa da absorbância diminuiu com o pré-tratamento de materiais lignocelulósicos, devido à degradação das ligações entre a lignina e carboidratos, além da degradação das pontes de hidrogênio entre as cadeias de celulose durante o processo de pré-hidrólise. 


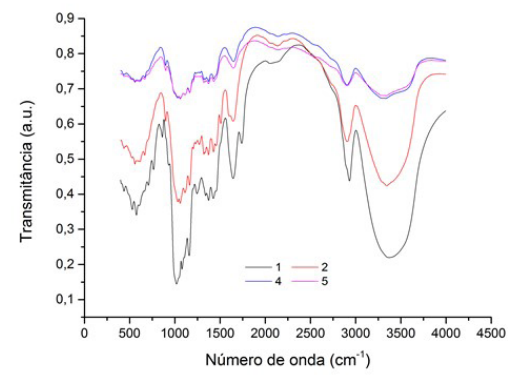

Figura 1. Espectros de FTIR.

\section{TGA}

As curvas de TGA apresentam três estágios de perda de massa:

i. Perda de água na amostra $\left(40-150^{\circ} \mathrm{C}\right)$;

ii. Degradação térmica da celulose $\left(215-350^{\circ} \mathrm{C}\right)$;

iii. Combustão de resíduos carbonáceos (acima de $350^{\circ} \mathrm{C}$ ).

As amostras de bagaço e tratadas com $\mathrm{HCl} 0,1 \mathrm{M}$ apresenta quatro estágios, sendo o terceiro de $350-550^{\circ} \mathrm{C}$, e o quarto de $550-800^{\circ} \mathrm{C}$. O bagaço de mandioca tratado apresentou maior estabilidade térmica que o bagaço in natura. Isto confirmou que o tratamento alcalino pode remover compostos de baixa estabilidade térmica, como amido, proteína, lipídeos e hemicelulose. Contudo, observa-se que a estabilidade térmica do bagaço após o branqueamento teve uma ligeira redução quando comparada com a amostra de tratamento alcalino. Isto é devido à remoção da lignina, que tem temperatura de decomposição maior que a celulose.

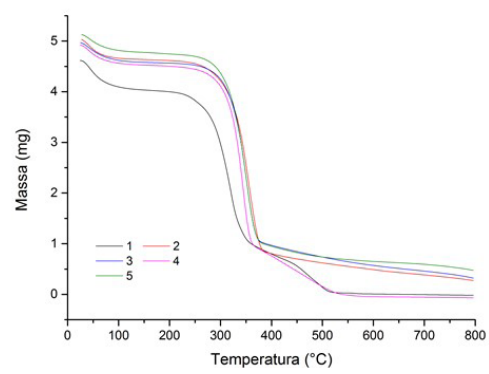

Figura 2. Curvas de TGA.

\section{MEV}

Nas Figuras 3, 4, 5, 6 e 7 encontram-se as imagens de microscopia eletrônica de varredura para as amostras 1, 2, 3, 4 e 5, respectivamente. A Figura 3 mostra a estrutura do bagaço de mandioca não tratado. Nesta, pode-se observar os grânulos de amido em grande quantidade, envolvidos pelas fibras. Nas imagens relativas às amostras subsequentes, não se encontra tais estruturas, indicando que o amido foi removido logo no início com o tratamento alcalino. Após o branqueamento (Figura 5) e as hidrólises ácidas (Figuras 6 e 7) observa-se uma rede fibrosa, de aparência semelhante à de um papel, não havendo alterações significativas na estrutura entre estas. Também é possível observar que as fibras têm, de fato, dimensões nanométricas.
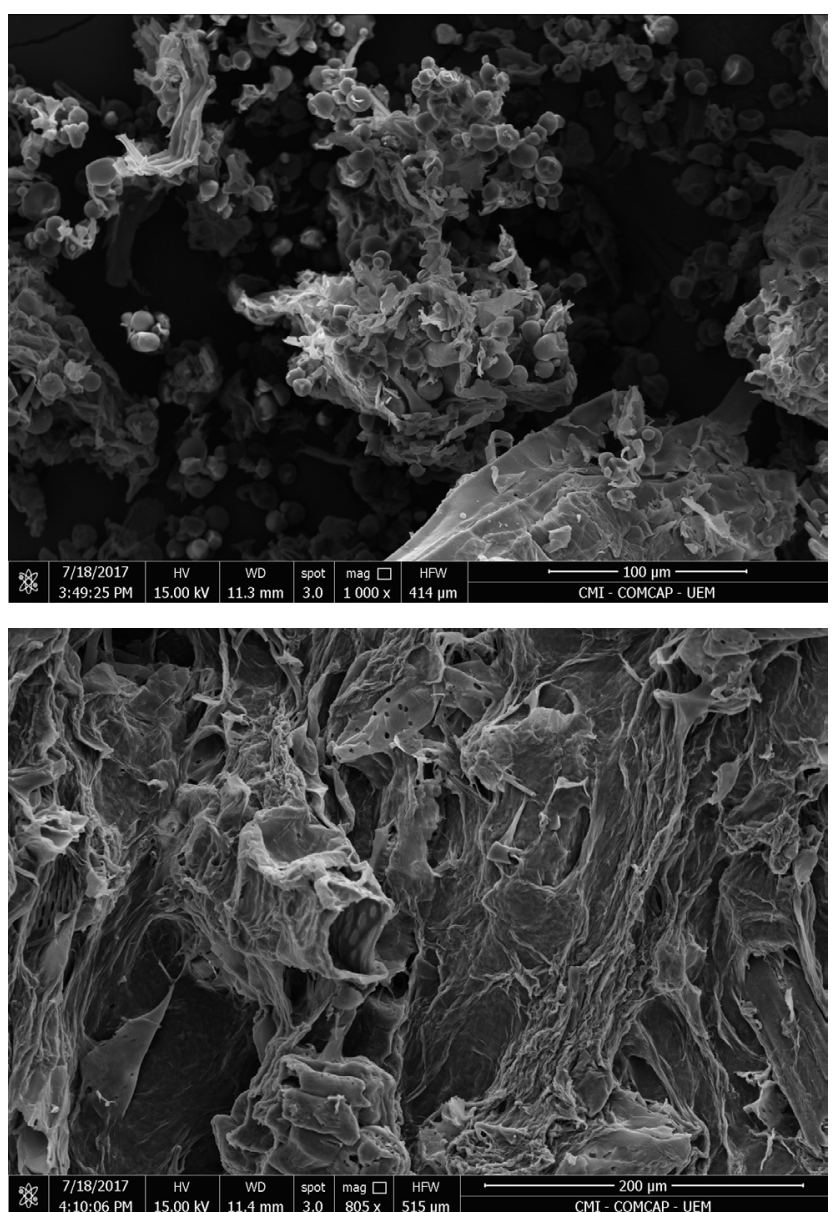

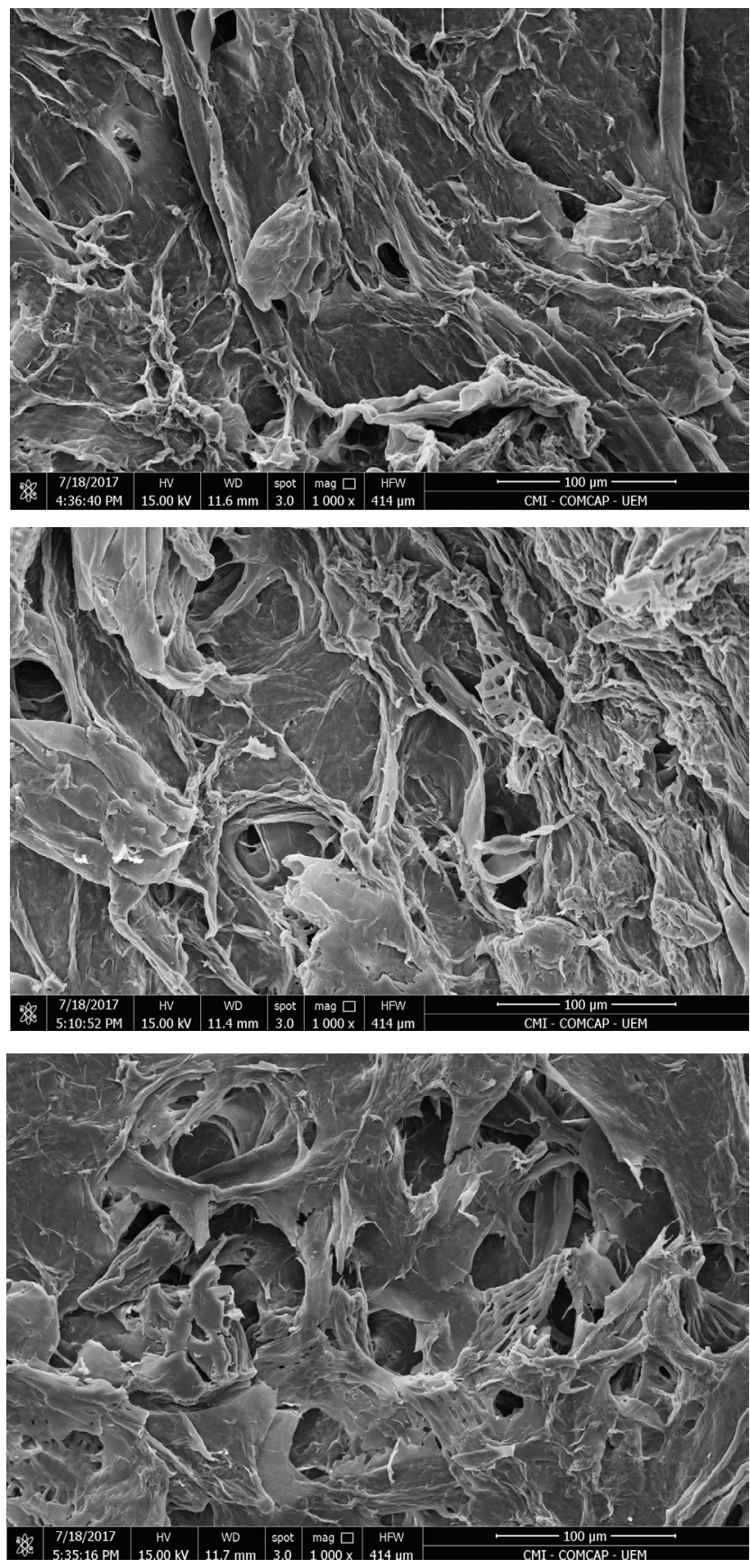

Figura 7. MEV para amostra 5.
Realizando uma análise visual macroscópica, percebese que a amostra 5 ficou mais clara e mais uniforme que a amostra 4, tendo esta última fibras mais grosseiras, como pode-se notar na Figura 8. Isto mostra que quanto mais forte ou mais concentrado o ácido, maior será a qualidade do produto final.

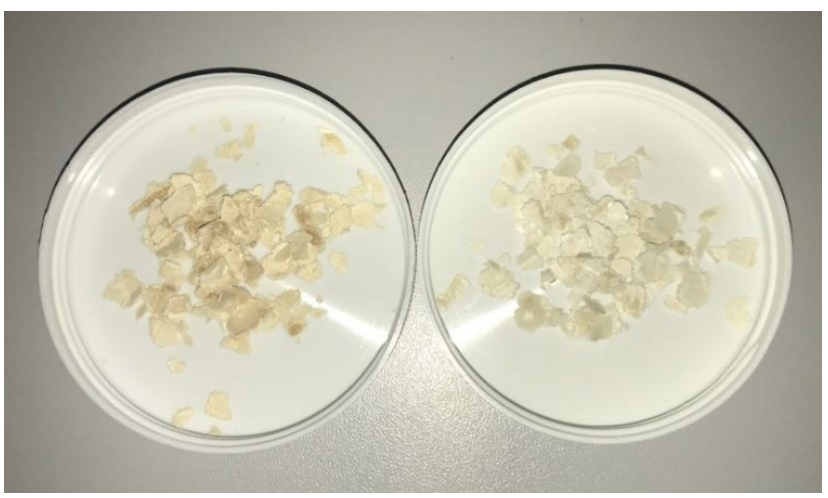

Figura 8. Amostra 4 (à esquerda) e amostra 5 (à direita).

A partir dos resultados obtidos, conclui-se que o tratamento alcalino é essencial para o isolamento das nanofibras, pois retira o amido e outros compostos de baixa estabilidade térmica (proteínas, lipídeos e hemicelulose) presentes no bagaço. O branqueamento ajuda a retirar a lignina do material e a hidrólise ácida atua na remoção de parte da lignina e da hemicelulose. Desta forma, quanto mais forte o ácido, mais eficaz é a retirada destes compostos.

Por fim, é possível isolar nanofibras de celulose de mandioca por meio de tratamentos químicos, o produto final é rico em celulose e termicamente mais estável que o bagaço. No entanto, a pesquisa está em andamento e são necessários mais estudos a fim de avaliar a composição centesimal das nanofibras como também analisar as propriedades dos filmes biodegradáveis após a incorporação destas. 


\section{Referências Bibliográficas}

1. Leite, A. L. M. P. Obtenção de nanofibras de celulose a partir de subprodutos da mandioca (Manihot esculenta Crantz). 2016. Tese (Mestrado em Engenharia de Alimentos) - Faculdade de Engenharia de Alimentos, Universidade Estadual de Campinas, Campinas. 2016.

2. Jasko, A. C.; Andrade, J., Campos, P. F.; Padilha, L.; Pauli, R. B.; Quast, L. B.; Schnitzler, E.; Demiate, I. M. Caracterização físico-química de bagaço de mandioca in natura e após tratamento hidrolítico. Revista Brasileira de Tecnologia Agroindustrial, v. 15, p. 427-441, 2011.

3. Nunes T. F. G. Produção, caracterização e aplicação de nanofibras de celulose. 2014. Tese (Mestrado Integrado em Engenharia Química) - Faculdade de Ciências e Tecnologia, Universidade de Coimbra, Coimbra, 2014.

4. Ruangudomsakul, W.; Ruksakulpiwat, C.; Ruksakulpiwat, Y. Preparation and Characterization of Cellulose Nanofibers from Cassava Pulp. Macromolecular Symposia, v. 354, n. 1, p. 170-176, ago. 2015.

5. Souza, R. G. Conjuntura Mensal - Mandioca: raiz, farinha e fécula. Companhia Nacional de Abastecimento - Ministério da Agricultura, Pecuária e Abastecimento. Disponível em: http://www.conab.gov.br/ OlalaCMS/uploads/arquivos/17_02_16_17_38_32_17.pdf. Acesso em: 24/08/2017.

\section{Isabella S. Silvestre \& Rita de Cássia Bergamasco*}

Universidade Estadual de Maringá. Maringá, PR, Brasil.

*E-mail: ritabergamasco@bol.com.br 